\title{
Second-Best Renewable Subsidies to De-carbonize the Economy: Commitment and the Green Paradox
}

\author{
Armon Rezai ${ }^{1,2,6}$ - Frederick van der Ploeg ${ }^{3,4,5}$
}

Accepted: 9 September 2016 / Published online: 23 November 2016

(C) The Author(s) 2016. This article is published with open access at Springerlink.com

\begin{abstract}
Climate change must deal with two market failures: global warming and learning by doing in renewable energy production. The first-best policy consists of an aggressive renewables subsidy in the near term and a gradually rising and falling carbon tax. Given that global carbon taxes remain elusive, policy makers might have to rely on a second-best subsidy only. With credible commitment the second-best subsidy is higher than the social benefit of learning to cut the transition time and peak warming close to first-best levels at the cost of higher fossil fuel use in the short run (weak Green Paradox). Without commitment the second-best subsidy is set to the social benefit of learning. It generates smaller weak Green Paradox effects, but the transition to the carbon-free takes longer and cumulative carbon emissions are higher. Under first best and second best with pre-commitment peak warming
\end{abstract}

Previous versions of this paper have benefited from helpful comments from Erik Ansink, Reyer Gerlagh, John Hassler, Per Krusell and seminar participants at Oxford, Tilburg and the Tinbergen Institute and audiences at Annecy, SURED 2014, Ascona, and WCERE 2014, Istanbul. The first author is grateful for financial support from the OeNB Anniversary Fund grant (Grant No. 15330) and a grant from the Austrian Science Fund (FWF): J 3633. The second is grateful for support from the ERC Advanced Grant 'Political Economy of Green Paradoxes' (FP7-IDEAS-ERC Grant No. 269788).

\footnotetext{
$凶 \quad$ Frederick van der Ploeg

rick.vanderploeg@economics.ox.ac.uk

Armon Rezai

armon.rezai@wu.ac.at

1 Department of Socioeconomics, Vienna University of Economics and Business, Welthandelsplatz 1, 1020 Vienna, Austria

2 IIASA, Schloßplatz 1, 2361 Laxenburg, Austria

3 Department of Economics, Oxford University, Manor Road Building, Manor Road, Oxford OX1 3UQ, UK

4 Laboratory Economic Performance and the Environment, State University of St. Petersburg, Sankt-Peterburg, Russia 199034

5 VU University Amsterdam, Amsterdam, The Netherlands

6 WIIW, Rahlgasse 3, 1060 Vienna, Austria
} 
is $2.1-2.3{ }^{\circ} \mathrm{C}$, under second best without commitment $3.5^{\circ} \mathrm{C}$, and without any policy $5.1^{\circ} \mathrm{C}$ above pre-industrial levels. Not being able to commit yields a welfare loss of $95 \%$ of initial GDP compared to first best. Being able to commit brings this figure down to $7 \%$.

Keywords First best - Second best - Commitment - Markov-perfect - Ramsey growth . Carbon tax $\cdot$ Renewables subsidy $\cdot$ Learning by doing $\cdot$ Directed technical change

JEL Classification H21 · Q51 · Q54

\section{Introduction}

Climate policy has to deal with two crucial market failures: the failure for markets to price carbon to fully internalize all future damages arising from burning another unit of carbon today (e.g., Nordhaus 2008; Stern 2013) and the failure of markets to internalize the full benefits of learning by doing in the production of renewable energy (e.g., Goulder and Mathai 2000; De Zwaan et al. 2002; Popp 2004; Edenhofer et al. 2005). To correct for these market failures the first-best policy has to be two-pronged: a carbon tax that must be set to the social cost of carbon (SCC) which equals the present value of all future marginal global warming damages resulting from burning one extra unit carbon today, ${ }^{1}$ and a renewable subsidy that must be set to the social benefit of learning by doing (SBL) which equals the present value of all future reductions in the cost of renewables from using one unit of renewable energy today. Politicians are, however, keener on the carrot than the stick and thus prefer subsidies to taxes. Thirty years of international climate negotiations have failed miserably and national renewable policies may be called for when agreements on international carbon taxation fail to materialize. This brings us in the realm of second-best economics. Our objective is, therefore, to investigate how well a second-best Markov-perfect optimal subsidy for renewable energy production $^{2}$ performs in the absence of a carbon tax in the decentralized market economy compared with the first-best climate policy and business as usual.

Second-best issues are omnipresent in public economics but rarely discussed in climate change economics. ${ }^{3}$ Grimaud et al. (2011) analyse optimal first-best and second-best climate policies in a decentralized market economy with directed technical change and endogenous growth. Kalkuhl et al. (2013) use a sophisticated IAM of growth and climate change with stock-dependent fossil fuel extraction costs to investigate the impact of optimal second-best renewable energy subsidies when carbon taxation is infeasible in a decentralized market

\footnotetext{
1 The optimal carbon price can be found on an efficient emissions market or as the shadow price of direct control legislation, but here we will refer to the carbon tax for sake of concreteness. Fischer et al. (2003) discusses effects of endogenous technical change on instrument choice.

2 In designing such a subsidy policy makers have to ensure that it is generic to avoid picking winners as policy makers have no particular ability to successfully pick the right renewable energy firm or technology to subsidize. It is thus important to have a broad market-based approach for stimulating the whole renewable energy industry (e.g., via tax deductions for all renewable energy producers).

3 The voluminous literature on the double dividend hypothesis surveyed by Bovenberg and Goulder (2002) deals with static second-best issues. The exceptions are Barrage (2014) and Schmitt (2013) who discuss optimal climate policy with distortionary labour and capital income taxation, respectively, with and without commitment. van der Ploeg (2016) discusses the theory of second-best optimal carbon taxation in a two-period, three-country framework, highlights the rent grabbing component of the unilateral carbon tax and shows that the second-best optimal future carbon tax given a first-best carbon tax that is set below the optimal social cost of carbon to mitigate weak Green Paradox effects.
} 
economy. ${ }^{4}$ These studies find that a second-best subsidy is an apt measure for compensating the missing carbon price but assume that policy makers can commit to announcements about future policies even though given the forward-looking nature of scarcity rents on fossil fuel there is an incentive to re-optimize and deviate from announcements about future policies. We therefore study the time-consistent Markov perfect second-best optimal policy and find that the loss of commitment has significant costs in terms of welfare and environmental damage. We characterize the equilibrium conditions for the first-best and second-best policy in an integrated assessment model (IAM) of growth and climate change with stock-dependent extraction costs, ongoing technical progress, and structural change. We assume that renewable energy is a perfect substitute for fossil fuel. ${ }^{5}$ This implies that there are discrete phases of energy use, which allow us to calculate the optimal second-best policies with and without commitment in a relatively straightforward way. We also assume that fossil fuel is exhaustible. The price of fossil fuel thus contains two forward-looking elements: the scarcity rent (the present discounted value of all future increases in extraction costs resulting from an extracting an extra unit of fossil fuel) and the carbon tax. The endogenous scarcity rent responds to expectations about future policy and in particular falls in response to expectations of future subsidies for renewable energy production. In the absence of a carbon tax, market prices for fossil fuel thus fall in this second-best setting, leading to increased carbon emissions relative to business as usual which has been coined a weak Green Paradox (Sinn 2008; Gerlagh 2011). The second-best Markov-perfect climate policy assumes, in contrast, that policy makers cannot commit to announced future renewable subsidies and therefore is set to the social benefit of learning. If commitment is credible, policy makers can improve on the Markov-perfect second-best optimal renewable subsidy by pushing the subsidy above the SBL, thereby compensating for the lack of a carbon tax. It brings forward extraction of fossil

\footnotetext{
${ }^{4}$ Kalkuhl et al. (2013) maximize welfare under the additional constraint of a peak warming of $2{ }^{\circ} \mathrm{C}$ and the associated cumulative carbon budget for the optimal first-best or second-best climate policies. In our framework policy has to trade off small reductions in future global warming against small reductions in consumption now. The resulting maximum degree of global warming depends on the rate of pure time preference, intergenerational inequality aversion and trend growth, and is thus not necessarily equal to $2^{\circ} \mathrm{C}$. In contrast to Kalkuhl et al. (2013), we find that the optimal second-best renewable subsidy is able to lock up a large fraction of fossil fuel reserves and thus despite some short-run adverse weak Green Paradox effects boosts welfare and gets close to the first-best optimum.

5 We suppose that the cost of renewable energy falls as experience increases (Arrow 1962). Tiang and Popp (2014) provide recent econometric evidence for significant learning-by-doing effects in renewable energy generation, which suggests that each new wind power project in China (with $60 \mathrm{GW}$ capacity) leads to a unit cost reduction of $0.25 \%$. De Zwaan et al. (2002) are the first to address optimal climate policy in the face of learning by doing in renewables in integrated assessment models. Popp (2004) studies endogenous technical progress in a fully calibrated IAM, Popp et al. (2010) review the implications of technical innovation and diffusion for the environment, and Goulder and Mathai (2000) study the implications in a stylized model of climate change. Manne and Richels (2004) argue that endogenous technical progress does not alter climate policy recommendations, specifically the transition timing. Jouvet and Schumacher (2012) find the opposite and so does Popp (2004) who studies optimal policies in an adapted version of DICE of Nordhaus (2008). Hübler et al. (2012) present a multi-region IAM with endogenous growth and study region-specific welfare effects. Fischer and Newell (2008) study optimal interaction of policy instruments in a calibrated model of heterogeneous energy producers limited to the US energy sector. None of these studies considers the "laissez faire" decentralized economy. Grimaud et al. (2001) characterize the "laissez faire" equilibrium in a stylized model. Various studies examine second-best carbon tax policy when not enough instruments are available to the government (Hart 2008; Graeker and Pade 2009). Second-best subsidies have been studied using large, numerical global energy models (Edenhofer et al. 2005; Bosetti et al. 2006). Fossil fuel stocks are assumed abundant. Thus these studies cannot address how much fossil fuel to lock up in the crust of the earth and the time of phasing in renewables does not depend on expectations about future policies and energy prices. These are crucial features of our analysis. Tsur and Zemel (2005) analyze growth and R\&D in a model with scarce resources, but do not offer a calibration and figures for optimal climate policy.
} 
fuel at the cost of accelerated global warming in the short run, because fossil fuel owners fear that their resources will be worth less in the future. However, compared with business as usual, either second-best policy locks up more fossil fuel in the ground and curbs global warming in the long run but less so than in the first best. Our second-best Markov-perfect framework allows to investigate whether the extra fossil fuel that is locked up forever is big enough to avoid a strong Green Paradox (Gerlagh 2011).

Our calibrated IAM suggests that the first-best climate policy requires an aggressive and temporary renewable subsidy for the next few decades and a gradually rising carbon tax to price out fossil fuel with the required carbon tax to keep out fossil fuel in the carbon-free era, eventually falling with time. Given our specification of global warming damages, the first-best climate policy enforces a carbon budget of $320 \mathrm{GtC}$ and brings down the maximum global mean temperature to $2.1^{\circ} \mathrm{C}$. With commitment the second-best subsidy for renewable energy fully compensates for the missing carbon tax such that the transition to carbon-free energy coincides with first-best. The lacking carbon tax, however, induces higher fossil fuel of 60 $\mathrm{GtC}$ during the fossil era and thus peak warming increases somewhat to $2.3^{\circ} \mathrm{C}$. The secondbest Markov-perfect renewable subsidy is relevant in the more realistic case that commitment is infeasible and uses a significantly higher carbon budget of $1080 \mathrm{GtC}$, which implies much higher peak warming of $3.5^{\circ} \mathrm{C}$. This compares to a business as usual outcome of $2500 \mathrm{GtC}$ carbon burnt and pre-industrial temperature increases of $5.1^{\circ} \mathrm{C}$. There is no strong Green Paradox as the Markov Perfect second-best renewable subsidy without commitment reduces social welfare relative to under first best by $95 \%$ of initial GDP compared to a welfare loss of six times initial GDP under business as usual. Being able to commit brings this figure down to $7 \%$. However, policy makers have an incentive to renege after some time has lapsed by increasing the renewable subsidy and bringing forward the carbon-free era even more and locking up even more carbon in the crust of the earth.

Section 2 discusses a simple two-stock model of carbon accumulation in the atmosphere and global mean temperature due to Golosov et al. (2014) and discusses our benchmark specification of climate damages which are bigger at higher temperatures than Nordhaus (2008, 2014) following recent suggestions by Stern (2013) and Dietz and Stern (2014). Section 3 formulates the command optimum for our general equilibrium IAM of climate change and Ramsey growth. Section 4 derives the market outcome of our IAM and shows how to derive the optimal first-best and second-best Markov-perfect climate policies. Section 5 offers policy simulations and highlights the effects of first-best and second-best Markovperfect climate policies on untapped fossil fuel, the time it takes to phase in renewable energy and to reach the carbon-free era, and welfare. There is also a discussion of the second-best optimal policy if pre-commitment is feasible. Section 6 concludes.

\section{The Carbon Cycle, Temperature and Global Warming Damages}

We use an annual version of the decadal model of the linear carbon cycle put forward by Golosov et al. (2014) and based on Archer (2005) and Archer et al. (2009):

$$
\begin{aligned}
& E_{t+1}^{P}=E_{t}^{P}+\varphi_{L} F_{t}, \quad \varphi_{L}=0.2, \quad E_{0}^{P}=103 G t C, \\
& E_{t+1}^{T}=(1-\varphi) E_{t}^{T}+\varphi_{0}\left(1-\varphi_{L}\right) F_{t}, \quad \varphi=0.002304, \quad \varphi_{0}=0.393, \quad E_{0}^{T}=699 G t C,
\end{aligned}
$$

where $E_{t}^{P}$ is the part of the stock of carbon $(\mathrm{GtC})$ that stays thousands of years in the atmosphere, $E_{t}^{T}$ the remaining part of the stock of atmospheric carbon $(\mathrm{GtC})$ that decays at 
rate $\varphi$, and $F_{t}$ the rate of fossil fuel use (GtC/decade). ${ }^{6}$ About $20 \%$ of carbon emissions stay up 'forever' and the remainder has a mean life of about 300 years, so $\varphi=1-(1-0.0228)^{1 / 10}=$ 0.002304 , where 0.0228 is the parameter proposed for the decadal model in Golosov et al. (2014). The parameter $\varphi_{0}=0.393$, is calibrated so that about half the carbon impulse is removed after 30 years.

The equilibrium climate sensitivity, $\omega$, is the rise in peak global mean temperature after a doubling of the total carbon stock in the atmosphere, $E_{t}$. A typical estimate for $\omega$ is 3 (IPCC 2007). Following Golosov et al. (2014), we ignore lags between atmospheric carbon and temperature:

$$
T_{t}=\omega \ln \left(E_{t} / 596.4\right) / \ln (2), \quad \omega=3, \quad E_{t} \equiv E_{t}^{P}+E_{t}^{T},
$$

where $596.4 \mathrm{GtC}$ is the IPCC figure for the pre-industrial carbon stock. ${ }^{7}$ The evolution of fossil fuel reserves $S_{t}$ (measured at the start of period $t$ ) follows from the depletion equation:

$$
S_{t+1}=S_{t}-F_{t}, \quad S_{0}=4000 G t C .
$$

Nordhaus (2008) combines detailed micro estimates of costs of global warming to get aggregate macro costs of $1.7 \%$ of world GDP at $2.5^{\circ} \mathrm{C}$. This figure is used to calibrate the fraction of production that is left after global warming damages:

$$
\tilde{Z}\left(T_{t}\right)=\frac{1}{1+\zeta_{1} T_{t}^{\zeta_{2}}+\zeta_{3} T_{t}^{\zeta_{4}}} \text {, so } Z\left(E_{t}\right) \equiv \tilde{Z}\left(\omega \ln \left(E_{t} / 596.4\right) / \ln (2)\right),
$$

with $\zeta_{1}=0.00284, \zeta_{2}=2$, and $\zeta_{3}=\zeta_{4}=0 .{ }^{8}$ Weitzman (2010) and Dietz and Stern (2014) argue that damages rise more rapidly at higher levels of temperature than suggested by (5). Assuming that damages are $50 \%$ of world GDP at $6^{\circ} \mathrm{C}$ and $99 \%$ at $12.5^{\circ} \mathrm{C}$, Ackerman and Stanton (2012) recalibrate (5) with $\zeta_{1}=0.00245, \zeta_{2}=2, \zeta_{3}=5.021 \times 10^{-6}$, and $\zeta_{4}=6.76$. The extra term in the denominator is included to capture potentially catastrophic losses at high temperatures. ${ }^{9}$

\section{Ramsey Growth and Climate Change: The Command Optimum}

The social planner maximizes utilitarian social welfare

$$
\sum_{t=0}^{\infty}(1+\rho)^{-t} L_{t} U_{t}\left(C_{t} / L_{t}\right)=\sum_{t=0}^{\infty}(1+\rho)^{-t} L_{t}\left[\frac{\left(C_{t} / L_{t}\right)^{1-1 / \eta}-1}{1-1 / \eta}\right],
$$

where $L_{t}$ is the size of the exogenous world population at time $t, C_{t}$ aggregate consumption at time $t, \quad U$ the instantaneous CES utility function, $\rho>0$ the rate of pure time preference and $\eta>0$ the elasticity of intertemporal substitution. The ethics of climate policy depend on

\footnotetext{
6 The three reservoirs used by Nordhaus (2008) highlight the exchange of carbon with the deep oceans, which arise from the acidification of oceans limiting the capacity to absorb carbon. Our carbon cycle ignores time-varying coefficients as in Bolin and Erikkson (1958). It also abstracts from diffusive rather than advective transfers of heat to the oceans (Allen et al. 2009) which leads to longer and greater warming (Bronselaer et al. 2013; Baldwin 2014).

7 This temperature lag lowers the SCC (Rezai and Van der Ploeg 2016).

8 The damage function resulting from the DICE-07 model is almost distinguishable (up to $7{ }^{\circ} \mathrm{C}$ ) from that of the DICE-2013R model (see http://www.econ.yale.edu/ nordhaus/homepage/Web-DICE-2013-April.htm).

9 We abstract from positive feedback and uncertain climate catastrophes (e.g., Lemoine and Traeger 2014; Lontzek et al. 2015; van der Ploeg and de Zeeuw 2013).
} 
how much weight is given to future generations and how small intergenerational inequality aversion (IIA $=1 / \eta$ ) is or how easy it is to substitute current for future consumption per head. The most ambitious climate policies result on a growth path, if society has a low rate of time preference and a low IIA (low $\rho$, high $\eta$ ).

Output is produced with capital $K_{t}$, labour, $L_{t}$, and energy. Energy is either renewable $R_{t}$ (e.g., solar or wind energy) or fossil fuel (oil, natural gas and coal) $F_{t}$. The production function $H($.) has constant returns to scale, is concave, and satisfies the Inada conditions. Renewables are subject to learning, so their unit production $\operatorname{cost} b\left(B_{t}\right)$ falls with cumulated past production $B_{t}$ and thus $b^{\prime}<0$. Fossil fuel extraction cost is $G\left(S_{t}\right) F_{t}$ with $S_{t}$ remaining reserves, and rise as less accessible fields have to be explored, $G^{\prime}<0$. What is left of production after covering the cost of energy is allocated to consumption $C_{t}$, investments $K_{t+1}-K_{t}$, and depreciation $\delta K_{t}$ where $\delta$ is the depreciation rate:

$$
K_{t+1}=(1-\delta) K_{t}+Z\left(E_{t}\right) H\left(K_{t}, L_{t}, F_{t}+R_{t}\right)-G\left(S_{t}\right) F_{t}-b\left(B_{t}\right) R_{t}-C_{t} .
$$

The initial capital stock $K_{0}$ is given. Renewable knowledge accumulates according to

$$
B_{t+1}=B_{t}+R_{t}, \quad B_{0}=0 .
$$

Current technological options favour fossil energy. Complete decarbonization requires substantial reductions in the cost of renewables versus that of fossil fuel. Apart from carbon taxes, technological progress is an important factor in determining the optimal combination of fossil and renewable energy sources (Acemoglu et al. 2012; Mattauch et al. 2012). We thus capture learning and lock-in effects by making the cost of renewables a decreasing function of past cumulated renewable energy production, $b^{\prime}<0$ with $B_{t}=\sum_{s=0}^{t} R_{s}$. We assume instantaneous and perfect spill-over of learning from one producer to all others. ${ }^{10}$

Proposition 1 The social optimum maximizes (6) subject to (1-8). It must satisfy the Euler equation for consumption growth

$$
\frac{C_{t+1} / L_{t+1}}{C_{t} / L_{t}}=\left(\frac{1+r_{t+1}}{1+\rho}\right)^{\eta}, \quad r_{t+1} \equiv Z_{t+1} H_{K_{t+1}}-\delta,
$$

and the efficiency conditions for energy use

$$
\begin{gathered}
Z\left(E_{t}\right) H_{F_{t}+R_{t}}\left(K_{t}, L_{t}, F_{t}+R_{t}\right) \leq G\left(S_{t}\right)+\theta_{t}^{S}+\theta_{t}^{E}, \quad F_{t} \geq 0, \quad \text { c.s. }, \\
Z\left(E_{t}\right) H_{F_{t}+R_{t}}\left(K_{t}, L_{t}, F_{t}+R_{t}\right) \leq b\left(B_{t}\right)-\theta_{t}^{B}, \quad R_{t} \geq 0, \quad \text { c.s. },
\end{gathered}
$$

where the scarcity rent, the SCC and the SBL are, respectively, given by

$$
\begin{aligned}
\theta_{t}^{S}= & -\sum_{s=0}^{\infty}\left[G^{\prime}\left(S_{t+1+s}\right) F_{t+1+s} \Delta_{t+s}\right], \\
\theta_{t}^{B}=- & \sum_{s=0}^{\infty}\left[b^{\prime}\left(B_{t+1+s}\right) R_{t+1+s} \Delta_{t+s}\right] \text { and } \\
\theta_{t}^{E}=- & \sum_{s=0}^{\infty}\left[\left\{\varphi_{L}+\varphi_{0}\left(1-\varphi_{L}\right)(1-\varphi)^{s}\right\}\right. \\
& \left.\Delta_{t+s} Z^{\prime}\left(E_{t+1+s}\right) H\left(K_{t+1+s}, L_{t+1+s}, F_{t+1+s}+R_{t+1+s}\right)\right],
\end{aligned}
$$

10 We prefer learning-by-doing over other specifications of endogenous technical change, such as investment in R\&D in Bovenberg and Goulder (1996) and Acemoglu et al. (2012), due to the better, albeit limited, availability of empirically validated learning curves. See also footnote 5 . 
with the compound discount factors given by $\Delta_{t+s} \equiv \prod_{s^{\prime}=0}^{s}\left(1+r_{t+1+s^{\prime}}\right)^{-1}, s \geq 0$.

Proof see Appendix A.

The Euler Eq. (9) states that growth in consumption per capita rises with the social return on capital $\left(r_{t+1}\right)$ and falls with the rate of time preference, especially if IIA $=1 / \eta$ is small. Equation (10a) states that, if fossil fuel is used, its marginal product should equal the sum of current extraction cost, $G\left(S_{t}\right)$, the scarcity rent, $\theta_{t}^{S}$, and the SCC, $\theta_{t}^{E}$. If fossil fuel is not used, its marginal product is below marginal cost. Equation (10b) indicates that, if renewable energy is used, its marginal product must equal its current cost $b\left(B_{t}\right)$ minus the SBL, $\theta_{t}^{B}$.

Equation (11) corresponds to the Hotelling rule which states that the return on extracting an extra unit of fossil, i.e., the rate of interest $\left(r_{t} \theta_{t}^{S}\right)$ minus the increase in future extraction $\operatorname{cost}\left(-G^{\prime}\left(S_{t+1}\right) F_{t+1}\right)$, must equal the expected capital gain from keeping an extra unit of fossil fuel in the earth $\left(\theta_{t+1}^{S}-\theta_{t}^{S}\right)$. Due to the availability of renewable energy as a backstop, increasing extraction costs imply that fossil fuel will be eventually phased out completely so that typically part of fossil fuel reserves will be abandoned and locked up. The Hotelling scarcity rent then captures the increase in all future extraction costs resulting from extracting an extra unit of fossil fuel today. Equation (12) indicates that the SBL equals the present discounted value of all future learning-by-doing reductions in the cost of renewable energy resulting from using one more unit of renewable energy today.

Equation (13) states that the SCC equals the present discounted value of all future marginal global warming damages from burning one unit of carbon today, taking due account of part staying in the atmosphere forever and the rest gradually decaying at a rate of roughly $1 / 300$ per year. A special case of our IAM yields the following simple rule for the SCC.

Proposition 2 If the utility function is logarithmic $(I I A=1)$, the production function is Cobb-Douglas, global warming damages are $Z\left(E_{t}\right) \cong \exp \left[-\tilde{\zeta}\left(E_{t}-581\right)\right]$ : depreciation of physical capital is $100 \%$ every period and energy production does not require capital input, the SCC becomes

$$
\theta_{t}^{E}=\tilde{\zeta}\left[\left(\frac{1+\rho}{\rho}\right) \varphi_{L}+\left(\frac{1+\rho}{\rho+\varphi}\right) \varphi_{0}\left(1-\varphi_{L}\right)\right] Z\left(E_{t}\right) H\left(K_{t}, L_{t}, F_{t}+R_{t}\right) .
$$

Proof see Golosov et al. (2014).

The simple rule $\left(13^{\prime}\right)$ states that the optimal SCC is proportional to world GDP. The factor of proportionality is independent of the factor production shares; it is big if society is patient ( $\rho$ small), the permanent fraction of the atmospheric stock of carbon $\varphi_{L}$ is large, and the lifetime of the transient component of the atmospheric stock of carbon $1 / \varphi$ is large. ${ }^{11}$

\section{Ramsey Growth and Climate Change: The Decentralized Market Outcome}

In a decentralized market economy one needs to consider the behaviour of producers of final goods, fossil fuel and renewable energy and that of households. Final goods producers operate under perfect competition. They take the output price (the numeraire), the wage $w_{t}$,

11 Nordhaus (1991) and Golosov et al. (2014) also give approximate rules for the optimal SCC, which depend on IIA and the trend rate of growth of the economy. Rezai and Van der Ploeg (2016) derive an approximate rule for the optimal SCC which also allows for population growth, climate damages not proportional to GDP, and mean reversion in damages to TFP growth and show that it performs very well. 
the market interest rate $r_{t+1}$, the market price for fossil fuel $p_{t}$, the specific carbon tax $\tau_{t}$, the market price for renewable energy $q_{t}$, the renewable subsidy $v_{t}$ and the carbon stock $E_{t}$ as given. They choose labour, capital and energy to maximize profits, $Z\left(E_{t}\right) H($. $)-w_{t} L_{t}-$ $\left(r_{t+1}+\delta\right) K_{t}-\left(p_{t}+\tau_{t}\right) F_{t}-\left(q_{t}-v_{t}\right) R_{t}$, where $r_{t+1}+\delta$ is the user cost of capital. This leads to the following efficiency conditions:

$$
\begin{aligned}
& Z\left(E_{t}\right) H_{K_{t}}=r_{t+1}+\delta, Z\left(E_{t}\right) H_{L_{t}}=w_{t}, \\
& \left.\begin{array}{l}
Z\left(E_{t}\right) H_{F_{t}} \leq p_{t}+\tau_{t} \\
F_{t} \geq 0
\end{array}\right\} \text { c.s. }, \\
& \left.\begin{array}{l}
Z\left(E_{t}\right) H_{R_{t}} \leq q_{t}-v_{t} \\
R_{t} \geq 0
\end{array}\right\} \text { c.s. }
\end{aligned}
$$

Making use of (14), we obtain the net output function

$$
Y_{t} \equiv Z\left(E_{t}\right) H(.)-\delta K_{t}-\left(p_{t}+\tau_{t}\right) F_{t}-\left(q_{t}-v_{t}\right) R_{t}=Y\left(E_{t}, K_{t}, L_{t}, p_{t}+\tau_{t}, q_{t}-v_{t}\right),
$$

where $Y_{E_{t}}=Z\left(E_{t}\right)^{\prime} H_{t}<0, \quad Y_{K_{t}}=r_{t+1}, \quad Y_{L_{t}}=w_{t}, \quad Y_{p_{t}+\tau_{t}}=-F_{t} \leq 0$ and $Y_{q_{t}-v_{t}}=$ $-R_{t} \leq 0$.

Fossil fuel owners also operate under perfect competition and maximize the present discounted value of their profits, $\sum_{t=0}^{\infty} \tilde{\Delta}_{t}\left[p_{t} F_{t}-G\left(S_{t}\right) F_{t}\right]$ with $\tilde{\Delta}_{t} \equiv \prod_{s=0}^{t}\left(1+r_{1+s}\right)^{-1}$, $t \geq 0$, subject to the depletion Eq. (4), taking the market price of fossil fuel $p_{t}$ as given and internalizing the adverse effect of current depletion on future extraction costs. They thus set the price of fossil fuel equal to extraction cost plus the scarcity rent (11) which stems from the Hotelling rule:

$$
p_{t}=G\left(S_{t}\right)+\theta_{t}^{S} \text { where } \theta_{t+1}^{S}=\left(1+r_{t+1}\right) \theta_{t}^{S}+G^{\prime}\left(S_{t+1}\right) F_{t+1} .
$$

Producers of renewable energy also operate under perfect competition and maximize the present value of their profits, $\sum_{t=0}^{\infty} \tilde{\Delta}_{t}\left[\left\{q_{t}-b\left(B_{t}\right)\right\} R_{t}\right]$, taking the market price of renewable energy $q_{t}$ and the stock of accumulated knowledge about using renewable energy $B_{t}$ as given. They thus set the price of renewable energy equal to the marginal cost of producing it: $q_{t}=b\left(B_{t}\right)$.

Households maximize utility (6) subject to the budget constraint $A_{t+1}^{H}=\left(1+r_{t+1}\right) A_{t}^{H}+$ $w_{t} L_{t}+\Theta_{t}-C_{t}$, where $A_{t}^{H}$ denotes household assets and $\Theta_{t}$ lump-sum transfers from the government. This gives rise to the same Euler equation for optimal consumption growth as in the command economy, (9).

The government balances its books, $\tau_{t} F_{t}=v_{t} R_{t}+\Theta_{t}$, so that it hands net revenue from taxes and subsidies as lump-sum transfers. Asset and final goods market equilibrium require $A_{t}^{H}=$ $K_{t}$ and $Z\left(E_{t}\right) H()=.C_{t}+K_{t+1}-(1-\delta) K_{t}+G\left(S_{t}\right) F_{t}+b\left(B_{t}\right) R_{t}$. Using (15) and the pricing conditions for energy producers, the latter becomes $K_{t+1}=K_{t}+Y_{t}-C_{t}+\left(\theta_{t}^{S}+\tau_{t}\right) F_{t}-v_{t} R_{t}$.

\subsection{Replicating the First-Best Optimum in the Market Economy}

The first fundamental theorem of welfare economics indicates that the first-best optimum for the command economy can, with suitable taxes and subsidies, be replicated in the market economy.

Proposition 3 The social optimum is replicated in the decentralized market economy if $\tau_{t}=\theta_{t}^{E}$ and $v_{t}=\theta_{t}^{B}, \forall t \geq 0$, where these follow from (12) and (13). 
Proof Comparing conditions of Proposition 2 with the efficiency conditions and market equilibrium conditions of the decentralized market economy, we can demonstrate that these are identical if the specific carbon tax is set to the first-best SCC and the renewable subsidy is set to the optimal SBL.

The first best thus emerges in the market economy if the specific carbon tax is set to the optimal SCC, the renewable subsidy is set to the optimal SBL, and net revenue is rebated in lump sums. There are also other ways of decentralizing the social optimum. For example, a global competitive emissions market will end up with a carbon price equal to the first-best SCC too.

\subsection{Second-Best Climate Policies in the Market Economy: With and Without Commitment}

As shown in Grimaud et al. (2011) and Kalkuhl et al. (2013), calculating second-best climate policies is more cumbersome. The reason is that the first fundamental theorem of welfare economic no longer holds if the full set of instruments is no longer available. This occurs if the government optimally chooses the renewable subsidy, but the carbon tax is absent (or constrained to a sub-optimal value). In this case, the renewable subsidy is set to maximize welfare subject to the behavioural, market equilibrium and budget constraints of the market economy as described in Sect. 4.1. Making use of the net output function (15), the government's second-best problem can thus be stated as:

$$
\operatorname{Max}_{\left\{v_{t}, t \geq 0\right\}} \sum_{t=0}^{\infty}(1+\rho)^{-t} L_{t}\left[\frac{\left(C_{t} / L_{t}\right)^{1-1 / \eta}-1}{1-1 / \eta}\right],
$$

subject to the constraints

$$
\begin{aligned}
& E_{t+1}^{P}=E_{t}^{P}+\varphi_{L} \operatorname{Max}\left[0,-Y_{p_{t}}\left(E_{t}, K_{t}, L_{t}, p_{t}, q_{t}-v_{t}\right)\right], \quad E_{0}^{P} \text { given, } \\
& E_{t+1}^{T}=(1-\varphi) E_{t}^{T}+\varphi_{0}\left(1-\varphi_{L}\right) \operatorname{Max}\left[0,-Y_{p_{t}}\left(E_{t}, K_{t}, L_{t}, p_{t}, q_{t}-v_{t}\right)\right], \quad E_{0}^{T} \text { given, }
\end{aligned}
$$

$S_{t+1}=S_{t}-\operatorname{Max}\left[0,-Y_{p_{t}}\left(E_{t}, K_{t}, L_{t}, p_{t}, q_{t}-v_{t}\right)\right], \quad S_{0}$ given,

$B_{t+1}=B_{t}+\operatorname{Max}\left[0,-Y_{q_{t}-v_{t}}\left(E_{t}, K_{t}, L_{t}, p_{t}, q_{t}-v_{t}\right)\right], \quad B_{0}=0$.

$K_{t+1}=K_{t}+Y\left(E_{t}, K_{t}, L_{t}, p_{t}, q_{t}-v_{t}\right)-C_{t}+\theta_{t}^{S} \operatorname{Max}\left[0,-Y_{p_{t}}\left(E_{t}, K_{t}, L_{t}, p_{t}, q_{t}-v_{t}\right)\right]$

$-v_{t} \operatorname{Max}\left[0,-Y_{q_{t}-v_{t}}\left(E_{t}, K_{t}, L_{t}, p_{t}, q_{t}-v_{t}\right)\right]$,

$$
\begin{aligned}
C_{t+1}= & \left(\frac{1+Y_{K_{t}}\left(E_{t}, K_{t}, L_{t}, p_{t}, q_{t}-v_{t}\right)}{1+\rho}\right)^{\eta}\left(\frac{L_{t+1}}{L_{t}}\right) C_{t}, \text { and } \\
\theta_{t+1}^{S}= & {\left[1+Y_{K_{t}}\left(E_{t}, K_{t}, L_{t}, p_{t}, q_{t}-v_{t}\right)\right] \theta_{t}^{S}+} \\
& \quad G^{\prime}\left(S_{t+1}\right) \operatorname{Max}\left[0,-Y_{p_{t+1}}\left(E_{t+1}, K_{t+1}, L_{t+1}, p_{t+1}, q_{t+1}-v_{t+1}\right)\right] .
\end{aligned}
$$

where $p_{t}=G\left(S_{t}\right)+\theta_{t}^{S}$ and $q_{t}=b\left(B_{t}\right)$. Equation (17) is the same objective as in (6) but with a different choice set. Equations (18a), (18b) and (18c) restate Eqs. (1), (2) and (4) with fossil fuel use substituted from the net output function (15). Equation (18d) describes the evolution of knowledge in producing renewable energy and stems from (6) and (15). Equation (18e) is the goods market equilibrium condition using (15). Equations (18a-e) give the dynamics for the predetermined state variables of our IAM. The dynamics for the non-predetermined 
states are given by the Euler equation for consumption (19a), which is derived from (9), and (19b) the Hotelling rule (19b) for the scarcity rent, which stems from (16), where the interest rate and fossil fuel use come from the net output function.

Given that empirically the cost of renewable energy is currently above that of fossil fuels, the second-best optimal outcome with pre-commitment for the market economy that results from the optimal control problem (17-19) consists of an initial phase where only fossil fuel is used, possibly an intermediate phase where fossil fuel and renewable energy use are alongside each other, ${ }^{12}$ and a final carbon-free phase. The renewable subsidy is only defined and effective during the intermediate and final renewable phase. The policy maker can bring forward the transition time to the carbon-free era by setting higher subsidy levels than the SBL, and thereby getting closer to the first best.

Such strategic considerations are not feasible for the policy maker without commitment: the Markov-perfect second-best policy therefore equals the SBL and does not attempt to manipulate the optimal time of transition to the carbon-free era. To see this, one has to solve the problem (17-19) using the principle of dynamic programming. Starting with the final phase, we note that the in-situ stock of fossil fuel remains unchanged whilst the carbon in the atmosphere gradually decays leaving ultimately only the permanent component. Since we have $Z\left(E_{t}\right) H_{R_{t}}=b\left(B_{t}\right)-v_{t}$, renewable use increases in capital, the stock of renewable knowledge and the renewable subsidy but falls with global warming. Working backwards in accordance with the principle of dynamic programming, we obtain the following proposition.

Proposition 4 During the final carbon-free phase and the phase where fossil fuel and renewable energy are used together, the Markov-perfect second-best optimal renewable subsidy equals the SBL:

$$
v_{t}=\theta_{t}^{B}=-\sum_{s=0}^{\infty}\left[b^{\prime}\left(B_{t+1+s}\right) R_{t+1+s} \Delta_{t+s}\right] .
$$

\section{Proof See Appendix B.}

The Markov-perfect second-best optimal renewable subsidy equals the second-best SBL, but this does not necessarily coincide with the first-best optimal SBL and renewable subsidy. To see this, note that the first phase where only fossil fuel is used has no policies and can be solved as if it were business as usual. Still, the outcomes during this first fossil-fuel-only phase are not business as usual for two reasons. First, the renewable subsidy with and without commitment ensures that more fossil fuel is locked up forever. This follows from the arbitrage condition that at the end of phase one (supposing that the intermediate phase is degenerate for the time being) the economy must be indifferent between using fossil fuel in final goods production and renewable energy and from a vanishing scarcity rent at that time:

$$
G\left(S_{t}\right)<b(0)-v_{t}, \quad 0 \leq t<t_{C F}, \quad G\left(S_{t}\right) \geq b\left(B_{t}\right)-v_{t}, \quad S_{t}=S_{t_{C F}}, \quad \forall t \geq t_{C F},
$$

where $t_{C F}$ is the time when the economy for the first time uses only renewable energy. From (21) we see that a renewable subsidy increases the stock of untapped fossil fuel and thus curbs the length of the first phase. Second, the renewable subsidy lowers fossil fuel

\footnotetext{
12 Since fossil fuel and renewable energy are perfect substitutes, simultaneous use is infeasible without learning by doing, renewable subsidy or carbon tax (except possibly for a single period of time). Learning by doing introduces convexity in the renewable production cost so an intermediate phase with simultaneous use might emerge. In fact, such a phase typically does not occur in our simulations and if it does occur it is at most for one or a few years.
} 
prices in the first phase and thus induces a weak Green Paradox as at any point of time carbon emissions are higher than under business as usual. A renewable subsidy thus curbs cumulative carbon emissions but boosts emissions in the short run.

At the time of the switch to the final carbon-free phase, the energy price must be continuous to rule out unexploited arbitrage opportunities. Hence, renewable energy use immediately after time $t_{C F}$ must equal fossil fuel use immediately before time $t_{C F}$, and thus is higher due to weak Green Paradox effects in the initial phase. The second-best optimal social benefit of learning by doing (20) must thus at time $t_{C F}$ and thereafter be higher than the first-best optimal SBL. In this sense the second-best optimal subsidy over-compensates for the lack of a carbon tax. The extent to which it is higher depends on the trade-off between adverse short-run weak Green Paradox effects and long-run benefits of locking up carbon. Hence, the upward adjustment of the SBL is less if fossil fuel demand is relatively elastic and fossil fuel supply is relatively inelastic. ${ }^{13}$

\subsection{Announcement of Future Second-Best Optimal Climate Policies}

As already mentioned, if policy makers can commit to announcements about the future renewable subsidy, they can boost welfare by pushing the renewable subsidy above the SBL and thereby bringing forward the carbon-free era, locking up more fossil fuel, and curbing cumulative carbon emissions. However, as is well known from the macroeconomic literature on time inconsistency (e.g., Kydland and Prescott 1977; Barro and Gordon 1983), such a policy - also called the rules outcome-is time inconsistent and not credible. ${ }^{14}$ As after some time there is less fossil fuel in situ, weak Green Paradox effects are less after some time. Re-optimization would then lead to an upward adjustment of the renewable subsidy. As a result, the phasing out of fossil fuel will be brought forward and less fossil fuel reserves will be burnt leading to lower cumulative carbon emissions and lower peak global warming, but transitory Green Paradox effects will be stronger. In our simulations we contrast the secondbest renewable policy with and without commitment, also called the rules and discretionary outcomes following Kydland and Prescott (1977), and highlight the cost of not being able to commit. We also show that welfare rises if policy makers renege on the former outcome just before the fossil fuel was meant to be phased out.

\section{Policy Simulation and Optimization}

Here we compare the scenarios for the market economy summarized in Fig. 1 and Tables 3-4:

I. the first-best outcome where the carbon tax is set to the optimal SCC, $\tau_{t}=\theta_{t}^{E}$, and the renewable subsidy is set to the optimal SBL, $v_{t}=\theta_{t}^{B}, \forall t \geq 0$ (solid lines);

II. the second-best renewable subsidy without commitment, also called the discretionary outcome(long-dashed lines);

\footnotetext{
13 One can also calculate the second-best carbon tax in the absence of a renewable subsidy. The derivation is similar and the global second-best carbon tax will be set to the SCC, where the SCC will differ due to the initial phase being longer and the in-situ stock of fossil fuel at the end of the initial phase being lower. With commitment the second-best carbon tax compensates for the lack of a renewable subsidy. Due to its political irrelevance, we do not study the second-best carbon tax further.

14 The co-states $\mu_{t}^{C}$ and $\mu_{t}^{S}$ for the non-predetermined variables driven by (19) are predetermined. Optimality requires that $\mu_{0}^{C}=0$ and $\mu_{0}^{S}=0$. The second-best optimal subsidy is time consistent if these co-states remain zero forever. If not, it is time inconsistent as it pays to renege and re-optimize.
} 
Table 1 Functional forms

Aggregate production function,

$$
\mathrm{H}\left(K_{t}, L_{t}, F_{t}+R_{t}\right)
$$$$
\left[(1-\beta)\left(A K_{t}^{\alpha}\left(A_{t}^{L} L_{t}\right)^{1-\alpha}\right)^{1-1 / \vartheta}+\beta\left(\frac{F_{t}+R_{t}}{\sigma}\right)^{1-1 / \vartheta}\right]^{\frac{1}{1-1 / \vartheta}}
$$

Extraction cost fossil energy, $G\left(S_{t}\right)$

$\gamma_{1}\left(S_{0} / S\right)^{\gamma_{2}}$

Generation renewable energy, $b\left(B_{t}\right)$

$\chi_{1}+\chi_{2} e^{-\chi_{3} B_{t}}$

Table 2 Key ethical and economic baseline parameter values

\begin{tabular}{llllllll}
\hline$\rho$ & $\eta$ & $A$ & $\alpha$ & $\beta$ & $\theta$ & $\delta$ & \\
$1 \%$ /year & $1 / 2$ & 3.78 & 0.35 & 0.06 & $1 / 2$ & $10 \% /$ year & $K_{0}$ \\
\hline$A_{0}^{L}$ & $\sigma$ & $\gamma_{1}$ & $\gamma_{2}$ & $\chi_{1}$ & $\chi_{2}$ & $\chi_{3}$ & $L_{0}$ \\
1 & 0.15 & 0.35 & 1 & 0.563 & 0.375 & 0.00375 & 6.5 \\
\hline
\end{tabular}

III. the second-best optimal renewable subsidy with pre-commitment, also called the rules outcome (short-dashed lines);

IV. BAU with no carbon tax or renewable subsidy (dot-dashed lines).

In our simulations time runs from 2010 till 2600 and is measured in years. ${ }^{15}$ The functional forms and calibration of the carbon cycle, temperature module and global warming damages have been discussed in Sect. 2. We choose standard macroeconomic parameter values for capital depreciation and intertemporal preferences and adopt assumptions on near-term productivity and population growth from Nordhaus (2014). Current production possibilities imply relatively low fossil fuel extraction costs and an initially high cost for renewable energy generation due to past biases in innovation towards fossil energy production. The calibration of our benchmark scenario reflects this cost structure. We report the functional forms and baseline values of our model put forward in Sects. 3 and 4 for key parameter in Tables 1, 2 and refer the reader to Appendix $\mathrm{C}$ for more calibration details.

We use a CES production function and elasticity of substitution between energy and the capital-labour aggregate of $\vartheta=0.5$. This determines the price elasticity of energy demand. The fossil fuel extraction cost function in Tables 1, 2 implies that the elasticity of abandoned fossil fuel reserves, $S(T)=S_{0}\left[\left(b\left(B_{T}\right)-v(T)\right) / \gamma_{1}\right]^{-1 / \gamma_{2}}$, with respect to the cost of renewable energy equals $1 / \gamma_{2}=1$. This figure can be interpreted as the price elasticity of fossil fuel supply, which we will return to in section 5.5.

\subsection{First Best: How to Quickly De-carbonize and Leave More Fossil Fuel Untapped}

Under the first-best scenario I (see the solid lines) consumption, GDP and the capital stock monotonically increase. The transition to renewable energy takes place smoothly as soon as

\footnotetext{
15 The problem is solved numerically with the optimization solver CONOPT3 in GAMS. We solve the model in finite time. The turnpike property ensures that all equilibrium paths approach the steady state quickly such that it renders terminal conditions essentially unimportant. In contrast to the first best, the second best needs additional constraints for market equilibrium and private sector behaviour.
} 

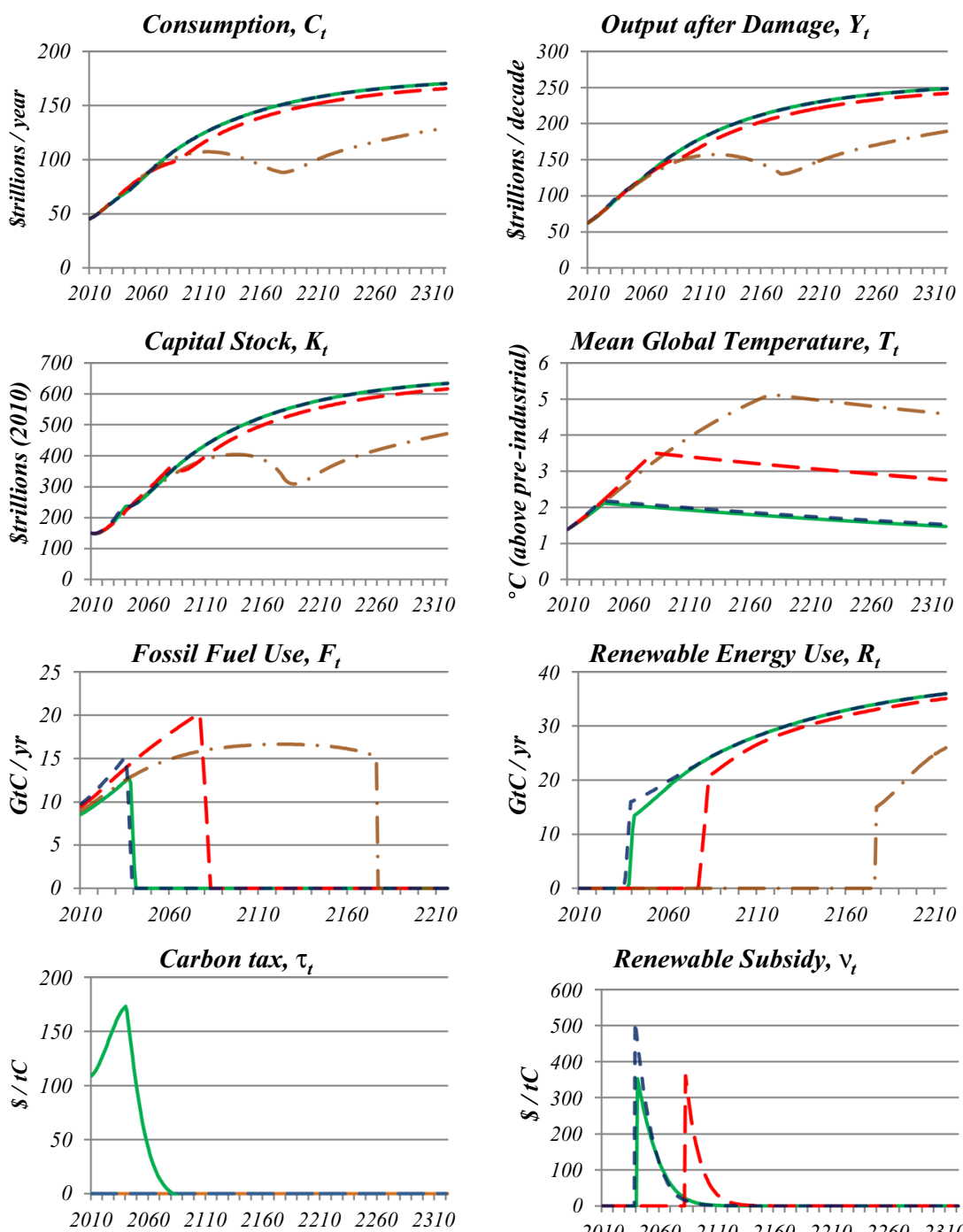

Renewable Subsidy, $v_{t}$

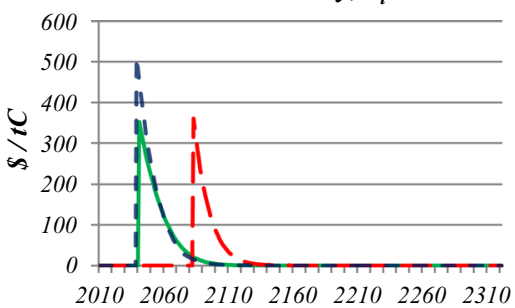

Cumulative Emissions
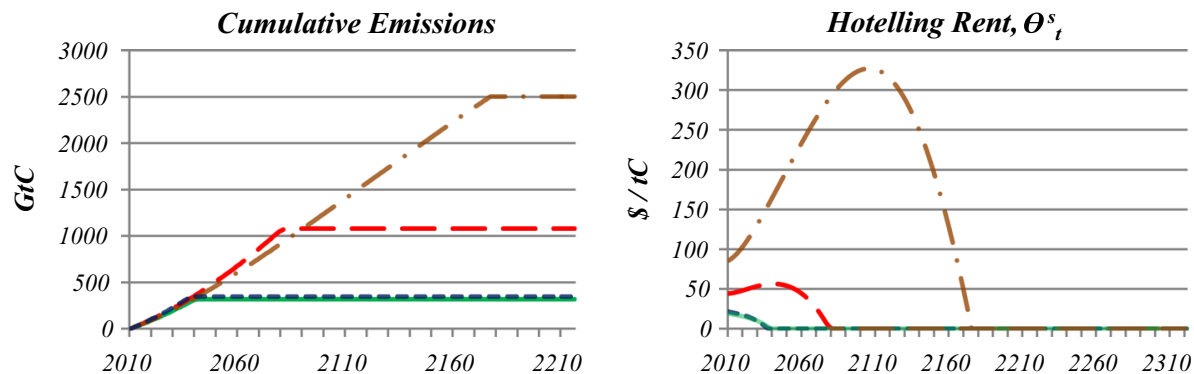

Fig. 1 Policy simulations. Key first best (solid lines), second-best subsidy: discretion (long-dashed lines), BAU (dot-dashed line), second-best subsidy: rules (short-dashed lines). (Color figure online) 
Table 3 Transition times and carbon budget

\begin{tabular}{llll}
\hline & Fossil fuel only & Renewable only & Carbon used \\
\hline I First best & $2010-2037$ & $2041-$ & $320 \mathrm{GtC}$ \\
II Second-best subsidy: no commitment (discretion) & $2010-2076$ & $2083-$ & $1080 \mathrm{GtC}$ \\
III Second-best subsidy: commitment (rules) & $2010-2035$ & $2040-$ & $345 \mathrm{GtC}$ \\
IV Business as usual & $2010-2176$ & $2177-$ & $2500 \mathrm{GtC}$ \\
\hline
\end{tabular}

Table 4 Global carbon taxes, renewable subsidies, and welfare losses

\begin{tabular}{|c|c|c|c|c|}
\hline & $\begin{array}{l}\text { Welfare loss } \\
(\% \text { of GDP) }\end{array}$ & $\begin{array}{l}\text { Maximum carbon } \\
\operatorname{tax} \tau(\$ / \mathrm{tC})\end{array}$ & $\begin{array}{l}\text { Maximum renewable } \\
\text { subsidy }(\$ / t C)\end{array}$ & $\begin{array}{l}\text { Peak T } \\
\left({ }^{\circ} \mathrm{C}\right)\end{array}$ \\
\hline I First best & $0 \%$ & $175 \$ / G t C$ & $350 \$ / \mathrm{GtC}$ & 2.1 \\
\hline $\begin{array}{l}\text { II Second-best subsidy: no } \\
\text { commitment }\end{array}$ & $-95 \%$ & N/A & $360 \$ / \mathrm{GtC}$ & 3.5 \\
\hline $\begin{array}{l}\text { III Second-best subsidy: } \\
\text { commitment }\end{array}$ & $-6 \%$ & N/A & $510 \$ / \mathrm{GtC}$ & 2.2 \\
\hline IV Business as usual & $-598 \%$ & N/A & N/A & 5.1 \\
\hline
\end{tabular}

2037; fossil energy is phased out completely by 2041 (see Table 3). Over this period $320 \mathrm{GtC}$ are burnt, so most of the $4000 \mathrm{GtC}$ of fossil fuel reserves are abandoned. Table 4 shows that this leads to a peak warming of only $2.1^{\circ} \mathrm{C}$ or a maximum atmospheric carbon stock of 970 GtC [from (3)], which is close to the maximum of a trillion tons of carbon argued for in Allen et al. (2009). ${ }^{16}$ This rapid and unambiguous first-best transformation towards a carbon-free economy is achieved through the implementation of a carbon tax and a renewable subsidy policy. Both follow an inverted U-shaped time profile. The global carbon tax starts at $109 \$ / \mathrm{tC}$ or $30 \$ / \mathrm{tCO} 2$ and reaches a maximum of $175 \$ / \mathrm{tC}$ or $48 \$ / \mathrm{tCO} 2$ at the end of the fossil era, after which the tax falls and becomes obsolete as learning in renewables reduces their cost. The renewable subsidy starts at $350 \$ / \mathrm{tC}$ or $95 \$ / \mathrm{tCO} 2$ in the first period of renewable use and rapidly falls to zero as all learning has occurred by the end of this century. The optimal policy mix, therefore, combines a quick and aggressive subsidy to phase in renewable energy quite early on and a carbon tax which gradually rises and falls to depress fossil energy use until renewable energy sources are competitive.

\subsection{Business as Usual and Markov-Perfect Second-Best Policies}

In the business as usual scenario IV (see the dot-dashed lines) both externalities remain uncorrected. As a result the economy uses much more fossil fuel: $2500 \mathrm{GtC}$ in total. Global mean temperature increases by a maximum of $5.1^{\circ} \mathrm{C}$ matching recent IPCC and IEA estimates for business as usual. The transition to renewable energy occurs much later, in 2176, and abruptly. The reason is that climate benefits of renewable energy and learning go unnoticed and are not fully internalized by the market. The impacts of the climate and learning externalities are large enough to drastically change accumulation paths as temperatures rise. This can be seen

16 Recent estimates by the IPCC (2014) state that cumulative emissions have to be limited to $790 \mathrm{GtC}$ (with an uncertainty range of 700-860 GtC) if global warming is to remain below $2^{\circ} \mathrm{C}$. By $2011520 \mathrm{GtC}$ had been emitted, giving a remaining carbon budget of only $270 \mathrm{GtC}$. 
in the "kinks" in the business-as-usual paths in Fig. 1 and is also reflected in the substantial welfare loss of about 6 times initial GDP. ${ }^{17}$ Failure to introduce climate policies induces a very long period of fossil fuel extraction leading to high cumulative carbon emissions and high global warming damages. Damages under business as usual are large enough to lower factor returns sufficiently to induce decumulation of capital and a fall in consumption. From $2140-2190$ the capital stock falls by $25 \%$ from a peak of $\$ 410$ trillion to a trough $\$ 310$ trillion, consumption drops by $17 \%$ from a peak of $\$ 107$ trillion to a trough of $\$ 88$ trillion. Once extraction costs rise above the cost of renewable energy, the fossil fuel era comes to an end. As the economy switches to renewable energy and stocks of atmospheric carbon recede, the return to capital, the interest rate and investment increase.

Failure to reach an international climate agreement on pricing carbon throughout the world or the political infeasibility of carbon taxes might lead to the implementation of a second-best renewable subsidy. Without commitment such a subsidy delays the transition by about 40 years (long-dashed red lines). The subsidy starts at a similar level as under first-best but the delayed transition increases total carbon use to $1080 \mathrm{GtC}$ (less than half of BAU but still 3 to 4 times the optimal carbon budget) and increases peak temperature significantly to $3.5^{\circ} \mathrm{C}$. The reduction of the carbon budget relative to BAU is, however, associated with a weak Green Paradox effect (Sinn 2008) in the absence of a correcting carbon tax, because fossil fuel use increases above BAU levels albeit for a shorter period (see Fossil Fuel Use panel in Fig. 1). ${ }^{18}$ In the long run more carbon is locked up in the crust of the earth than under BAU. As a result of this, welfare is higher than under BAU and there is no strong Green Paradox effect. The cost of second-best is significant as welfare falls by $95 \%$ compared to the first best, but this fall is substantially less than the fall of almost 6 times initial GDP under BAU.

\subsection{Second-Best Renewable Subsidy with Pre-commitment and Time Inconsistency}

To facilitate comparison with Kalkuhl et al. (2013), we also indicate in Fig. 1 (see the shortdashed lines) the effects of second-best optimal renewable subsidies when pre-commitment is feasible. It is clear from the simulations that with pre-commitment the renewable subsidy is pushed above the SBL as this brings forward the carbon-free era by more than four decades relative to the case without commitment and close to the first-best timing (from 2083 to 2040). It also locks up more fossil fuel in the crust of the earth. There is some acceleration of global warming in the short run arising from the weak Green Paradox effect, but more fossil fuel is locked up in the long run and therefore cumulative emissions and peak global warming are cut down (from 1080 to $345 \mathrm{GtC}$ and from 3.5 to $2.2^{\circ} \mathrm{C}$ ). Although carbon emissions are higher by $25 \mathrm{GtC}$ and global mean temperature by $0.1^{\circ} \mathrm{C}$ relative to the firstbest outcome, this is exclusively due to short-run weak Green Paradox effects. In the absence of carbon taxation, fossil fuel prices are depressed relative to BAU under the second-best subsidy for renewable energy as global warming is forced down to a figure that is very close to the first-best outcome. To mimic the first-best outcome while having to accept somewhat higher fossil fuel use during the fossil era, renewable energy needs to be phased in earlier than first-best. These inefficiencies are relatively small and welfare falls by less than $6 \%$

\footnotetext{
17 Stern (2007) expresses cost of inaction in annuity terms; Nordhaus (2008) in terms of today's consumption. We calculate the difference in the total welfare, evaluated at initial prices, and express it as a share of initial GDP. Our welfare measure equals the loss due to inaction as a share of initial GDP.

18 Under Leontief production technology, there are no Green Paradox effects as the energy demand is a fixed proportion of output.
} 
relative to the first-best outcome, which is a lot less than the loss of 95\% of initial GDP if pre-commitment to future climate policies is infeasible.

Alas, the pledges of policy makers regarding the second-best optimal policy with commitment are not credible if commitment breaks down and there is an incentive to deviate from the initial policy announcement later on. To illustrate this time inconsistency, we give policy makers the option to re-optimize after 25 years. This leaves only 5 years of fossil fuel use and $55 \mathrm{GtC}$ to be burnt. Policy makers renege on their announcements by subscribing to more ambitious climate targets: the subsidy for renewable energy is increased by almost $10 \%$ to $50 \$ / \mathrm{tC}$ and as a result cumulative carbon emissions are depressed by nearly $15 \mathrm{GtC}$ as the linkage to the weak Green Paradox effect with higher fossil fuel use in the first 25 years is severed. In choosing to surprise private agents by pushing up subsidies for renewable energy, expectations are falsified and welfare is increased by $0.1 \%$ and peak temperature is lowered by a tiny amount $\left(0.03^{\circ} \mathrm{C}\right)$ relative to the second-best outcomes. This occurs at the expense of a tiny additional weak Green Paradox effect. This illustrates that, in the absence of a credible and effective commitment mechanism, the second-best renewable subsidies calculated under the assumption are pre-commitment are likely to be reneged on and are thus time inconsistent. If pre-commitment cannot be guaranteed, the second-best renewable energy subsidies calculated under the assumption of no pre-commitment and discussed in Sect. 5.2 will be relevant as they are credible and time consistent albeit at the expense of lower welfare and higher peak warming. Our results demonstrate the importance of commitment devices in climate policy.

\subsection{Time Paths for the Market Price of Fossil Fuel and Renewable Energy}

The weak Green Paradox effects are best seen when plotting the market prices of energy, depicted in Fig. 2. The price of fossil energy consists of the sum of marginal extraction cost and the Hotelling rent plus any carbon tax [see Eq. (10a)]. The market price of renewable energy is set to its production cost minus any learning subsidy [see Eq. (10b)]. Initially prices are rising in all scenarios and only on these rising sections are fossil fuels used. The solid black line gives the initial cost of renewable energy.

First, consider the business as usual scenario IV (see the dot-dashed line) where the carbon tax and the subsidy are set to zero. The market cost of renewable energy is above the market price of fossil energy and constant without any learning by doing through learning by doing from past production and/or subsidy. Fossil fuel is in use initially and its price rises due to increasing extraction costs and the increasing Hotelling rents. As extraction costs approach the back-stop price, the fossil fuel era draws to an end and the Hotelling rent falls. This fall in the Hotelling rent mitigates rising extraction costs and prolongs the era of fossil fuel use. In its final period, the scarcity value reaches zero and extraction costs equal renewable unit costs. After this switch point, the cost of fossil energy, consisting now only of the extraction cost component, remains constant. Due to learning by doing, the cost of producing renewable energy falls quickly and approaches its lower floor.

With a second-best subsidy without commitment, scenario II (see the long-dashed line), the market price of energy falls below its business-as-usual level as fossil fuel owners anticipate that their resources will be worth less in the future. Lower market prices temporarily stimulate higher fossil fuel use (of up to 28\%), faster extraction, and acceleration of global warming. Once the SBL is sufficiently high to make fossil fuel uncompetitive, renewable energy is produced and energy prices start to fall as past learning lowers production costs. 
Fig. 2 The market prices of energy during the transition (\$/tC). Key first best (solid lines), second-best subsidy: discretion (long-dashed lines), BAU (dot-dashed line), second-best subsidy: rules (short-dashed lines). (Color figure online)

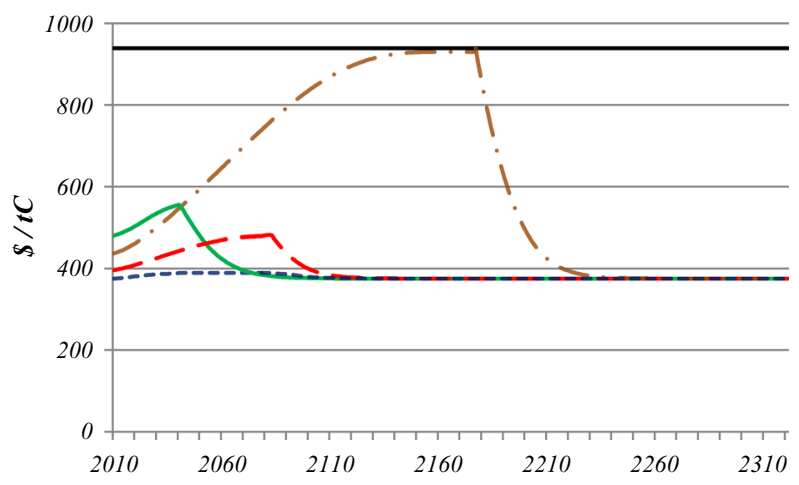

First best policy, scenario I (see the solid line), precludes the weak Green Paradox effect by setting a carbon tax which equals the SCC. This lifts energy prices above BAU levels initially. The tax allows enables an earlier transition to renewable energy.

The second-best subsidy with pre-commitment, scenario III (see the short-dashed line) compensates for the missing carbon tax by increasing the renewable energy subsidy beyond the SBL. Energy prices are lower initially and kept lower for longer as the subsidy prices fossil energy out of the market to ensure learning makes renewable energy competitive even as the subsidy recedes.

\subsection{Robustness of Optimal Climate Policy}

Table 5 shows the sensitivity of all policy scenarios to key parameter values. It can be shown analytically that a higher price elasticity of energy demand and a lower price elasticity of fossil fuel reserves increase the magnitude of the Green Paradox effect and thus strengthen the importance of the ability to commit (van der Ploeg 2016). To illustrate this, we first increase the elasticity of substitution between energy and the other inputs in the aggregate production function from $\vartheta=0.5$ to 1 as this corresponds to a higher price elasticity of energy demand. The higher price elasticity allows substitution away from fossil fuel in each period, so in the first-best scenario less carbon is used although the transition occurs later. The decrease in fossil fuel consumption also delays the climate crisis and ameliorates the fall in consumption so that the welfare loss under BAU falls considerably relative to the baseline case of less substitutability. The substitutability of fossil fuel, however, heightens the short-run Green Paradox effects and the welfare loss under commitment increase in absolute terms and under the absence of commitment relative to BAU.

In contrast, we also increase the convexity of extraction costs by increasing $\gamma_{2}$ from 1 to 2 and thereby lower the price elasticity of final fossil fuel reserves from 1 to 0.5 . This severely limits the economic viability of fossil fuels and reduces the carbon budget by as much as one third relative to the baseline calibration. Lower cumulative fossil fuel lowers the Hotelling rent and now limits the Green Paradox effect. The value of commitment, measured in the welfare reduction in the loss of commitment, falls almost by one half.

We also present simulations for variations in the rate of productivity growth and the pure time preference. Lowering productivity growth makes climate policy more ambitious (with an intertemporal inequality aversion greater than 1) as future generations will have lower material well-being and lower levels of climate damage are justified. The carbon budgets and peak warming relative to baseline do not change significantly, however, as fossil fuel is used 


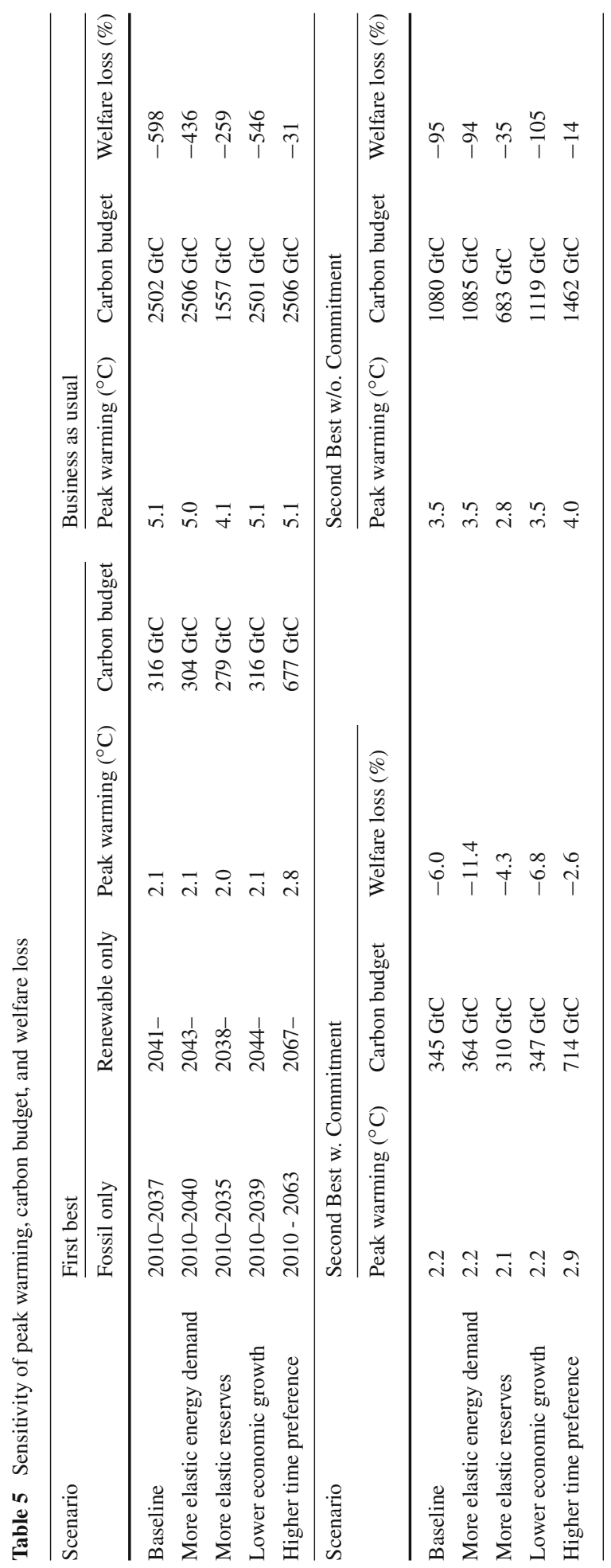


at a lower rate for longer. A higher rate of pure time preference increases the consumption discount rate which makes climate policy less ambitious and lowers the social cost of carbon. Peak warming and the carbon budget increase significantly to $2.8^{\circ} \mathrm{C}$ and $677 \mathrm{GtC}$. The consumption discount rate, however, also lowers the trend growth rate of the economy and ameliorates the problems of the climate externality and commitment.

\section{Conclusion}

Our integrated assessment of climate change and Ramsey growth highlights the costs associated with second-best climate policies which apply when policy makers fail to price carbon. While the first-best climate policy prices carbon and subsidizes renewable use to curb fossil fuel use, promote substitution away from fossil fuel towards renewable energy sources, increase untapped fossil fuel, and bring forward the carbon-free era, we show that secondbest policy has significant costs in terms of welfare and peak warming. The first-best policy mix limits the total amount of carbon burnt to $320 \mathrm{GtC}$ and peak warming to $2.1{ }^{\circ} \mathrm{C}$, whereas under the Markov-perfect second-best policy $1080 \mathrm{GtC}$ are burnt and temperature rises by as much as $3.5^{\circ} \mathrm{C}$. The associated welfare loss amounts to nearly today's world GDP compared to a welfare loss of almost 6 times today's world GDP under business as usual which sees global warming rise to $5.1^{\circ} \mathrm{C}$ as the total amount of carbon burnt is much higher $(2500 \mathrm{GtC})$. A subsidy to renewable energy without taxing fossil fuel encourages higher fossil fuel use in the short run (up to $30 \%$ above fossil fuel use under business as usual), but locks up more carbon and curbs cumulative carbon emissions.

Previous studies on second-best climate policy have assumed, somewhat unrealistically, that pre-commitment to announced policies by policy makers is possible, thus finding that the absence of a carbon tax does not add significant welfare losses. Our results show that these findings are due to the assumption of commitment which allows an energy transition that is very close to the first best. Due weak Green Paradox effects, however, cumulative carbon emissions increase by 25 to $345 \mathrm{GtC}$ and peak warming to $2.3^{\circ} \mathrm{C}$. This slight increase in temperature lowers welfare by $6 \%$ of initial GDP. Welfare is higher than under business as usual (no strong Green Paradox effect), since the second-best optimal subsidy locks up more carbon in the earth and limits peak global warming. However, the second-best policy is not credible as it pays policy makers to renege and push up the renewable energy subsidy even more after some time has lapsed.

Business as usual induces peak warming of $5.1{ }^{\circ} \mathrm{C}$. The welfare loss without policy is almost 6 times today's world GDP. Second-best renewable subsidies are, therefore, better than doing nothing, but are insufficient to combat climate change. It is important that renewable subsidies are complemented by a carbon tax to avoid excessive extraction in the short run associated with the weak Green Paradox effect. If policy makers can pre-commit to announced renewable subsidies, they can do better but they would have an incentive to renege and therefore such announcements are not credible.

Our main message is that one has to be careful in taking second-best policies at face value, when it turns out that they are derived under the assumption of credible commitment to future policies. Such commitment to future climate policies is rarely seen which leads to much less ambitious the second-best optimal climate policies. A crucial direction of research for economists, lawyers, and political scientists interested in climate policy is to examine how such commitment can be brought about. Fortunately, there is a voluminous literature in macroeconomics and monetary economics to draw on. For example, Barro and Gordon 
(1983) show that, in an infinitely repeated game between policy makers and private agents, sufficient reputation can be built up for the policy makers not to renege on their announcements provided that the discount rate is not too high and punishments for deviating from the rules outcome are high enough. If policy makers have insufficient reputation, they have to fall back on the less attractive discretion outcome. More interesting is perhaps Rogoff's (1985) argument that the political process appoints a president of the central bank who is more conservative (inflation averse) than the median (and pivotal) voter. Monetary economists have long advocated that commitment to a sound monetary policy requires a clear and simple mandate and an independent central bank. Adapting these arguments, Helm et al. (2003) argue for a politically independent central carbon bank. Such a carbon bank should be free of political influences, be given a clear mandate of ensuring that temperature will never exceed $2{ }^{\circ} \mathrm{C}$, and be headed by a president committed to even more stringent policy. Such institutions can help to build commitment to a credible climate policy.

Finally, we should make a caveat. Our IAM features perfect substitution between fossil fuel and renewable energy. This leads to discrete phases of energy use, which thankfully makes the calculation of the second-best policies with and without commitment relatively straightforward. Although this assumption gives clear insights into the levers of time-inconsistent policies, when one has imperfect substitution between fossil fuel and renewable energy the calculation of solving the second-best optimal policies without commitment requires solving intricate dynamic programming problems. ${ }^{19}$ This is the challenge for future research.

Open Access This article is distributed under the terms of the Creative Commons Attribution 4.0 International License (http://creativecommons.org/licenses/by/4.0/), which permits unrestricted use, distribution, and reproduction in any medium, provided you give appropriate credit to the original author(s) and the source, provide a link to the Creative Commons license, and indicate if changes were made.

\section{Appendix A: Proof of Proposition 1}

The adjoined Lagrangian for our model reads:

$$
\begin{aligned}
& L \equiv \sum_{t=0}^{\infty}(1+\rho)^{-t}\left[L_{t} U_{t}\left(C_{t} / L_{t}\right)-\mu_{t}^{S}\left(S_{t+1}-S_{t}+F_{t}\right)-\mu_{t}^{B}\left(B_{t+1}-B_{t}-R_{t}\right)\right] \\
& \quad+\sum_{t=0}^{\infty}(1+\rho)^{-t}\left[\mu_{t}^{P}\left(E_{t+1}^{P}-E_{t}^{P}-\varphi_{L} F_{t}\right)+\mu_{t}^{T}\left\{E_{t+1}^{T}-(1-\varphi) E_{t}^{T}-\varphi_{0}\left(1-\varphi_{L}\right) F_{t}\right\}\right] \\
& \quad-\sum_{t=0}^{\infty}(1+\rho)^{-t} \lambda_{t} \\
& {\left[K_{t+1}-(1-\delta) K_{t}-Z\left(E_{t}^{P}+E_{t}^{T}\right) H\left(K_{t}, L_{t}, F_{t}+R_{t}\right)+G\left(S_{t}\right) F_{t}+b\left(B_{t}\right) R_{t}+C_{t}\right], }
\end{aligned}
$$

where $\mu_{t}^{S}$ denotes the shadow value of in-situ fossil fuel, $\mu_{t}^{B}$ the shadow value of learning by doing, $\mu_{t}^{P}$ and $\mu_{t}^{T}$ the shadow disvalue of the permanent and transient stocks of atmospheric carbon, and $\lambda_{t}$ the shadow value of manmade capital. Necessary conditions for a social opti-

19 One could make use of the sophisticated dynamic programming algorithms used in Lemoine and Traeger (2014) and Lontzek et al. (2015), but these will require a lot of adaptation as the second-best Markov-perfect optimization problem cannot be solved as a command optimum. 
mum are:

$$
\begin{aligned}
& U^{\prime}\left(C_{t} / L_{t}\right)=\left(C_{t} / L_{t}\right)^{-1 / \eta}=\lambda_{t}, \\
& Z_{t} H_{F_{t}+R_{t}} \leq G\left(S_{t}\right)+\left[\mu_{t}^{S}+\varphi_{L} \mu_{t}^{P}+\varphi_{0}\left(1-\varphi_{L}\right) \mu_{t}^{T}\right] / \lambda_{t}, \quad F_{t} \geq 0, \quad \text { c.s., } \\
& Z_{t} H_{F_{t}+R_{t}} \leq b\left(B_{t}\right)-\mu_{t}^{B} / \lambda_{t}, \quad R_{t} \geq 0, \quad \text { c.s. } \\
& \left(1-\delta+Z_{t+1} H_{K_{t+1}}\right) \lambda_{t+1}=(1+\rho) \lambda_{t}, \\
& \mu_{t+1}^{S}=(1+\rho) \mu_{t}^{S}+G^{\prime}\left(S_{t+1}\right) F_{t+1} \lambda_{t+1}, \\
& \mu_{t+1}^{B}=(1+\rho) \mu_{t}^{B}-b^{\prime}\left(B_{t+1}\right) R_{t+1} \lambda_{t+1}, \\
& \mu_{t+1}^{P}=(1+\rho) \mu_{t}^{P}+Z^{\prime}\left(E_{t+1}^{P}+E_{t+1}^{T}\right) H_{t+1} \lambda_{t+1}, \\
& (1-\varphi) \mu_{t+1}^{T}=(1+\rho) \mu_{t}^{T}+Z^{\prime}\left(E_{t+1}^{P}+E_{t+1}^{T}\right) H_{t+1} \lambda_{t+1} \text {. }
\end{aligned}
$$

Equations (22a) and (22d) yield the Euler Eq. (9). The Kuhn-Tucker conditions (22b) and (22c) give (10a) and (10b) after defining $\theta_{t}^{S} \equiv \mu_{t}^{S} / \lambda_{t}, \theta_{t}^{B} \equiv \mu_{t}^{B} / \lambda_{t}$ and $\theta_{t}^{E} \equiv$ $\left[\varphi_{L} \mu_{t}^{P}+\varphi_{0}\left(1-\varphi_{L}\right) \mu_{t}^{T}\right] / \lambda_{t}$ in final good units. (22e) and (22d) yield the Hotelling rule

$$
\theta_{t+1}^{S}=\left(1+r_{t+1}\right) \theta_{t}^{S}+G^{\prime}\left(S_{t+1}\right) F_{t+1} .
$$

Forward summation over time of (23) and using the transversality conditions gives (11). Equations (22f) and (22d) yield

$$
\theta_{t+1}^{B}=\left(1+r_{t+1}\right) \theta_{t}^{B}+b^{\prime}\left(B_{t+1}\right) R_{t+1} .
$$

Forward summation over time of (24) and using the transversality conditions yields (12). Defining $\theta_{t}^{P} \equiv \mu_{t}^{P} / \lambda_{t}$ and $\theta_{t}^{T} \equiv \mu_{t}^{T} / \lambda_{t}$ in final good units we use (22g), (22h) and (22a) to get:

$$
\begin{aligned}
\theta_{t+1}^{P} & =\left(1+r_{t+1}\right) \theta_{t}^{P}+Z^{\prime}\left(E_{t+1}^{P}+E_{t+1}^{T}\right) H_{t+1}, \\
(1-\varphi) \theta_{t+1}^{T} & =\left(1+r_{t+1}\right) \theta_{t}^{T}+Z^{\prime}\left(E_{t+1}^{P}+E_{t+1}^{T}\right) H_{t+1} .
\end{aligned}
$$

Solving (25a) and (25b), using the transversality conditions and $\theta_{t}^{E} \equiv \varphi_{L} \theta_{t}^{P}+\varphi_{0}\left(1-\varphi_{L}\right) \theta_{t}^{T}$, we obtain Eq. (13).

\section{Appendix B: Proof of Proposition 4}

The Lagrangian for the final phase of the second-best outcome is defined as

$$
\begin{aligned}
& \Lambda \equiv \sum_{t=t_{R}}^{\infty}(1+\rho)^{-t} L_{t}\left[\frac{\left(C_{t} / L_{t}\right)^{1-1 / \eta}-1}{1-1 / \eta}\right] \\
& +\lambda_{t}^{B}\left[B_{t+1}-B_{t}+Y_{b\left(B_{t}\right)-v_{t}}\left(E_{t}, K_{t}, L_{t}, ., b\left(B_{t}\right)-v_{t}\right)\right] \\
& +\lambda_{t}^{K}\left[K_{t+1}-K_{t}-Y\left(E_{t}, K_{t}, L_{t}, ., b\left(B_{t}\right)-v_{t}\right)\right. \\
& \left.+C_{t}-v_{t} Y_{b\left(B_{t}\right)-v_{t}}\left(E_{t}, K_{t}, L_{t}, ., b\left(B_{t}\right)-v_{t}\right)\right] \\
& +\mu_{t}^{C}\left[C_{t+1}-\left(\frac{1+Y_{K_{t+1}}\left(E_{t+1}, K_{t+1}, L_{t+1}, ., b\left(B_{t+1}\right)-v_{t+1}\right)}{1+\rho}\right)^{\eta}\left(\frac{L_{t+1}}{L_{t}}\right) C_{t}\right] \text {, }
\end{aligned}
$$


where $t_{C F}$ denotes the start of the final carbon-free phase. The optimality conditions for this phase are

$$
\begin{aligned}
& \frac{d \Lambda}{d v_{t}}=\left(\lambda_{t}^{K} v_{t}-\lambda_{t}^{B}\right) Y_{q_{t}, q_{t}}+\eta \mu_{t-1}^{C} Y_{K_{t}, q_{t}}\left(\frac{1+r_{t}}{1+\rho}\right)^{\eta-1}\left(\frac{L_{t}}{L_{t-1}}\right) C_{t-1}=0, \\
& \frac{d \Lambda}{d B_{t}}=(1+\rho) \lambda_{t-1}^{B}-\lambda_{t}^{B} \\
& +\left[\lambda_{t}^{B} Y_{q_{t}, q_{t}}+\lambda_{t}^{K}\left(R_{t}-v_{t} Y_{q_{t}, q_{t}}\right)\right. \\
& \left.-\eta \mu_{t-1}^{C} Y_{K_{t}, q_{t}}\left(\frac{1+r_{t}}{1+\rho}\right)^{\eta-1}\left(\frac{L_{t}}{L_{t}-1}\right) C_{t-1}\right] b^{\prime}\left(B_{t}\right)=0, \\
& \frac{d \Lambda}{d K_{t}}=\lambda_{t}^{B} Y_{K_{t}, q_{t}}+(1+\rho) \lambda_{t-1}^{K}-\lambda_{t}^{K}\left(1+r_{t}+v_{t} Y_{K_{t}, q_{t}}\right) \\
& -\eta \mu_{t-1}^{C} Y_{K_{t}, K_{t}}\left(\frac{1+r_{t}}{1+\rho}\right)^{\eta-1}\left(\frac{L_{t}}{L_{t-1}}\right) C_{t-1}=0 . \\
& \frac{d \Lambda}{d C_{t}}=\left(C_{t} / L_{t}\right)^{-1 / \eta}+\lambda_{t}^{K}+(1+\rho) \mu_{t-1}^{C}-\mu_{t}^{C}\left(\frac{1+r_{t+1}}{1+\rho}\right)^{\eta}\left(\frac{L_{t+1}}{L_{t}}\right)=0 .
\end{aligned}
$$

One can verify that the optimal Markov-perfect second-best renewable subsidy is time consistent in the final phase by verifying that a solution to (18), (19) and (21) exists if $\mu_{t}^{C}=0, t \geq 0$. Let us suppose this is the case, We then get from (27a) that $v_{t}=\lambda_{t}^{B} / \lambda_{t}^{K}$, so tha (27b) gives $(1+\rho) \lambda_{t-1}^{B}=\lambda_{t}^{B}+\lambda_{t}^{K} b^{\prime}\left(B_{t}\right) R_{t}$ and $(27 \mathrm{c})$ gives $(1+\rho) \lambda_{t-1}^{K}=\lambda_{t}^{K}\left(1+r_{t+1}\right)$. Equation $(27 \mathrm{~d})$ yields $L_{t}\left(C_{t} / L_{t}\right)^{1-1 / \eta}+\lambda_{t}^{K}=0$, which together with the last condition yields the Euler equation (19a). We also have $(1+\rho) v_{t-1} \lambda_{t-1}^{K}=v_{t} \lambda_{t}^{K}+\lambda_{t}^{K} b^{\prime}\left(B_{t}\right) R_{t}$ or $v_{t}=\left(1+r_{t+1}\right) v_{t-1}-+b^{\prime}\left(B_{t}\right) R_{t}$, which indeed yields (20) and is the same as (12).

Using a similar procedure, one show that the Markov-perfect renewable phase during the phase were fossil fuel and renewable energy are used alongside each other is given by the same expression for the SBL.

\section{Appendix C: Functional Forms and Calibration}

Our model runs on an annual instead of decadal time grid as earlier integrated assessment models or semi-decadal as in Nordhaus (2014). This allows us to pinpoint much more accurately the transition times towards the carbon-free era and a coarse time grid has been shown to introduce significant numerical biases (Cai et al. 2012).

\subsection{Preferences}

We have CES utility and set the elasticity of intertemporal substitution to $\eta=1 / 2$ and thus intergenerational inequality aversion to 2 . The rate of pure time preference $\rho$ is $1 \%$ per year.

\subsection{Cost of energy}

We employ an extraction technology of the form $G(S)=\gamma_{1}\left(S_{0} / S\right)^{\gamma_{2}}$, where $\gamma_{1}$ and $\gamma_{2}$ are positive constants. This specification implies that reserves will not be fully be extracted; some fossil fuel remains untapped in the crust of the earth. Extraction costs are calibrated to give an initial share of energy in GDP between 6-7\% depending on the policy scenario. This 
translates to fossil production costs of $\$ 350 / \mathrm{tC}$ ( $\$ 35 / \mathrm{barrel}$ of oil), where we take one barrel of oil to be equivalent to $1 / 10$ ton of carbon, giving $G\left(S_{0}\right)=\gamma_{1}=0.35$. The IEA (2008) long-term cost curve for oil extraction gives a doubling to quadrupling of the extraction cost of oil if another $1000 \mathrm{GtC}$ are extracted. Since we are considering all carbon-based energy sources (not only oil) which are more abundant and cheaper to extract, we assume only a doubling of production costs if a total $2000 \mathrm{GtC}$ is extracted. With $S_{0}=4000 \mathrm{GtC},{ }^{20}$ this gives $\gamma_{2}=1 .^{21}$ This implies that we assume very low extraction costs and a high initial stock of reserves which biases our findings toward using more fossil fuel longer.

\subsection{Initial capital stock and depreciation rate}

The initial capital stock is set to 200 (US\$ trillion), which is taken from Rezai et al. (2012). We set the depreciation rate $\delta$ to be 0.1 per year.

\subsection{Global production and global warming damages}

Output before damages is

$$
\begin{aligned}
H_{t} & =\left[(1-\beta)\left(A K_{t}^{\alpha}\left(A_{t}^{L} L_{t}\right)^{1-\alpha}\right)^{1-1 / \vartheta}+\beta\left(\frac{F_{t}+R_{t}}{\sigma}\right)^{1-1 / \vartheta}\right]^{\frac{1}{1-1 / \vartheta}}, \\
\vartheta & \geq 0,0<\alpha<1 \text { and } 0<\beta<1 .
\end{aligned}
$$

This is a constant-returns-to scale CES production function in energy and a capitallabour composite with $\theta$ the elasticity of substitution and $\beta$ the share the parameter for energy. The capital-labour composite is defined by a constant-returns-to-scale CobbDouglas function with $\alpha$ the share of capital, $A$ total factor productivity and $A_{t}^{L}$ the efficiency of labour. The two types of energy are perfect substitutes in production. Damages are calibrated so that they give the same level of global warming damages for the initial levels of output and mean temperature. We rewrite production before damages as $H_{t}=$ $H_{0}\left[(1-\beta)\left(\frac{A K_{t}^{\alpha}\left(A_{t}^{L} L_{t}\right)^{1-\alpha}}{H_{0}}\right)^{1-1 / \vartheta}+\beta\left(\frac{F_{t}+R_{t}}{\sigma H_{0}}\right)^{1-1 / \vartheta}\right]^{\frac{1}{1-1 / \vartheta}}$. We set the share of capital to $\alpha=0.35$, the energy share parameter to $\beta=0.06$, and the elasticity of factor substitution $\vartheta=0.5$ (as in the WITCH 2008 model) which we will refer to as the CES run. Initial world GDP in 2010 is $\$ 63$ trillion. Given $A_{1}^{L}=1$, we calibrate $A=3.78$ to yield initial output under "laissez faire". The energy intensity of output $\sigma$ is calibrated to an initial energy use of 9,5 GtC under "laissez faire", $\sigma=0.15$.

\subsection{Population growth and labour-augmenting technical progress}

Population in $2010\left(L_{1}\right)$ is 6.5 billion people. Following Nordhaus (2008) and UN projections population growth is given by $L_{t}=8.6-2.1 e^{-0.35 t}$. Population growth starts at $1 \%$ per year and falls below $0.1 \%$ percent within six decades and flattens out at 8.6 billion people. In the sensitivity analysis in Sect. 4.3 we assume faster growth and a higher plateau to reflect more recent forecasts. Without loss of generality the efficiency of labour $A_{t}^{L}=3-2 e^{-0.2 t}$ starts

\footnotetext{
20 Stocks of carbon-based energy sources are notoriously hard to estimate. IPCC (2007) assumes in its A2scenario that $7000 \mathrm{GtCO}_{2}$ (with $3.66 \mathrm{tCO} 2$ per tC this equals $1912 \mathrm{GtC}$ ) will be burnt with a rising trend this century alone. We roughly double this number to get our estimate of $4000 \mathrm{GtC}$ for initial fossil fuel reserves. Nordhaus (2008) assumes an upper limit for carbon-based fuel of $6000 \mathrm{GtC}$ in the DICE-07.
}

21 Since $G(2000) / G(4000)=(4000 / 2000)^{\gamma_{2}}=2^{\gamma_{2}}$ and $2^{\gamma_{2}}=2$. 
out with $A_{1}^{L}=1$ and an initial Harrod-neutral rate of technical progress of $2 \%$ per year. The efficiency of labour stabilizes at 3 times its current level.

\subsection{Cost of the renewable and learning by doing}

We model learning by doing with initial cost reductions and a lower limit for the cost of the renewable, i.e., $b\left(B_{t}\right)=\chi_{1}+\chi_{2} e^{-\chi_{3} B_{t}}, \chi_{1}, \chi_{2}, \chi_{3} \geq 0$. This formulation differs from the usual power law definition of learning curves (Manne and Richels 2004) but allows us to better calibrate initial learning rates (which can reach infinity for power law) and specify a lower limit for unit cost. We calibrate unit cost of renewable energy to the percentage of GDP necessary to generate all energy demand from renewables. Under a Leontief technology, with $\vartheta \rightarrow 0$, energy demand is $\sigma Z_{t} H_{t}$. The cost of generating all energy carbon free is $\sigma Z_{t} H_{t} b / Z_{t} H_{t}=\sigma b_{t}$. Nordhaus (2008) states that it costs $5.6 \%$ of GDP to decarbonize today's economy in a model of back-stop mitigation. We increase this cost to 7-8\% of GDP in order to reach the learning potential given below. To calibrate the production cost of renewable energy, this cost estimate needs to be combined with the cost of producing conventional energy which ranges between 6 and 7\%. This gives $\sigma b_{1}=0.14$ or with $\sigma=0.15$ we get $b_{1}=b(0)=\chi_{1}+\chi_{2}=0.94$ or $\$ 940 / \mathrm{tC}$. Through learning by doing this cost can be reduced by $60 \%$ to a lower limit of $9 \%$ of GDP, so that $b(\infty)=\chi_{1}=0.563$ and thus $\chi_{2}=0.375$. In our simulations with $\vartheta>0$, this lower limit falls to about $6 \%$ of GDP due to substitution of energy through capital, i.e. in the long run the share of energy falls back to its current level. We assume that experience in renewable production lowers unit cost at a falling rate and the parameter $\chi_{3}$ measures this speed of learning. We calibrate learning such that costs would decrease slowly. We suppose a mere $1.25 \%$ reduction in cost if all of world energy use would be supplied by renewable sources in the initial period, so that $\chi_{3}=0.00375$. These assumptions imply at most a $14 \%$ reduction for a doubling of experience at the peak of learning-by-doing and fall within the broad range reported for learning rates in renewable generation (McDonald and Schrattenholzer, 2001). Manne and Richels (2004) use a $20 \%$ cost reduction for a doubling of experience (and thus need to impose unrealistic constraints on renewable use due to the strong curvature of the power-law learning curve). Alberth and Hope (2007) assume a cost reduction of 5-25\% for a doubling of experience so our calibrated 14\% falls in this range. Goulder and Mathai (2000) calibrate their learning-by-doing technology to a $0.5-4 \%$ of GDP cost of a $25 \%$ emission reduction in 2020. This translates into a cost of renewable energy which is a factor 3-8 times current fossil energy prices. In our calibration current renewable production prices are little less than 3 times those of fossil energy. These numbers illustrate the large scientific uncertainties surrounding the possible trajectories of renewable energy prices. Our calibration falls within the ballpark figures presented above, providing higher costs relative to Nordhaus (2008) who also considers potential CCS technologies in his assessment.

\section{References}

Acemoglu D, Aghion P, Bursztyn L, Hemous D (2012) The environment and directed technical change. Am Econ Rev 102(1):131-166

Ackerman F, Stanton E (2012) Climate risks and carbon prices: revising the social cost of carbon. Econ Open-Access, Open-Assess E-J 6:10

Alberth S, Hope C (2007) Climate modelling with endogenous technical change: stochastic learning and optimal greenhouse gas abatement in the PAGE2002 model. Energy Policy 35(3):1795-1807 
Allen M, Frame D, Huntingford C, Jones C, Lowe J, Meinshausen M, Meinshausen N (2009) Warming caused by cumulative carbon emissions towards the trillionth tonne. Nature 458(7242):1163-1166

Archer D (2005) The fate of fossil fuel CO2 in geologic time. J Geophys Res 110:C09S05

Archer D, Eby M, Brovkin V, Ridgwell A, Cao L, Mikolajewicz U, Caldeira K, Matsumoto K, Munhoven G, Montenegro A, Tokos K (2009) Atmospheric lifetime of fossil fuel carbon dioxide. Annu Rev Earth Planet Sci 37:117-134

Arrow K (1962) The economic implications of learning by doing. Rev Econ Stud 29:155-173

Baldwin E (2014) The social cost of carbon and assumed damages from high temperatures. Mimeo, University of Oxford

Barrage L (2014) Optimal dynamic carbon taxes in a climate-economy model with distortionary fiscal policy. Brown University, Providence

Barro RJ, Gordon DB (1983) A positive theory of monetary policy in a natural-rate model. J Polit Econ 91(4):589-610

Bolin B, Eriksson B (1958) Changes in the carbon dioxide content of the atmosphere and sea due to fossil fuel combustion. In: Bolin B (ed) The atmosphere and the sea in motion: scientific contributions to the Rossby memorial volume. Rockefeller Institute Press, New York, pp 130-142

Bosetti V, Carraro C, Galeotti M (2006) The dynamics of carbon and energy intensity in a model of endogenous technical change. Energy J 27:191-205

Bovenberg A, Goulder L (2002) Optimal environmental taxation in the presence of other taxes: generalequilibrium analysis. Handb Public Econ 3:1471-1545

Bovenberg A, Smulders J (1996) Transitional impacts of environmental policy in an endogeneous growth model. Int Econ Rev 37(4):861-893

Bronselaer B, Zanna L, Lowe JA, Allen MR (2013) Examining the time scales of atmosphere-ocean carbon and heat fluxes. Mimeo

Cai Y, Judd K, Lontzek T (2012) Open science is necessary. Nat Clim Change 2:299

Dietz S, Stern NH (2014) Endogenous growth, convexity of damages and climate risk: how Nordhaus' framework supports deep cuts in carbon emissions. Econ J 125:574-620

Edenhofer E, Bauer N, Kriegler E (2005) The impact of technological change on climate protection and welfare: insights from the model MIND. Ecol Econ 54:277-292

Fischer C, Parry I, Pizer W (2003) Instrument choice for environmental protection when technological innovation is endogenous. J Environ Econ Manag 45(3):523-545

Fischer C, Newell R (2008) Environmental and technology policies for climate mitigation. J Environ Econ Manag 55:142-162

Goulder L, Mathai K (2000) Optimal CO2 abatement in the presence of induced technological change. J Environ Econ Manag 39:1-38

Gerlagh R (2011) Too much oil. CESifo Econ Stud 57(1):79-102

Golosov M, Hassler J, Krusell P, Tsyvinski A (2014) Optimal taxes on fossil fuel in general equilibrium. Econometrica 82(1):41-88

Graeker M, Pade L-L (2009) Optimal carbon dioxide abatement and technological change: should emission taxes start high in order to spur R\&D? Clim Change 96(3):335-355

Grimaud A, Lafforgue G, Magné B (2011) Climate change mitigation options and directed technical change: a decentralized equilibrium analysis. Resour Energy Econ 33(4):938-962

Hart R (2008) The timing of taxes on CO2 emissions when technological change is endogenous. J Environ Econ Manag 55(2):194-212

Helm D, Hepburn C, Mash R (2003) Credible carbon policy. Oxf Rev Econ Policy 19(3):438-450

Hübler M, Baumstark L, Leimbach M, Edenhofer O, Bauer N (2012) An integrated assessment model with endogenous growth. Ecol Econ 83:118-131

IEA (2008) World energy outlook 2008, http://www.iea.org/textbase/nppdf/free/2008/weo2008.pdf

IPCC (2007) Climate change 2007, the Fourth IPCC Assessment Report. http://www.ipcc.ch/ipccreports/ar4syr.htm

Jouvet P-A, Schumacher I (2012) Learning-by-doing and the costs of a backstop for energy transition and sustainability. Ecol Econ 73:122-132

Kalkuhl M, Edenhofer O, Lessmann K (2013) Renewable energy subsidies: second-best policy or fatal aberration for mitigation? Resour Energy Econ 35(3):217-234

Kydland FE, Prescott EC (1977) Rules rather than discretion: the inconsistency of optimal plans. J Polit Econ 85(3):473-492

Lemoine D, Traeger CP (2014) Watch your step: optimal policy in a tipping climate. Am Econ J Econ Policy 6:137-166

Lontzek TS, Cai Y, Judd KL, Lenton TM (2015) Stochastic integrated assessment of climate tipping points calls for strict climate policy. Nat Clim Change 5:441-444 
Manne A, Richels R (2004) The impact of learning-by-doing on the timing and costs of CO2 abatement. Energy Econ 26:603-619

Mattauch L, Creutzig F, Edenhofer O (2012) Avoiding carbon lock-in: policy options for advancing structural change, Working Paper No. 1-2012, Climatecon

McDonald A, Schrattenholzer L (2000) Learning rates for energy technologies. Energy Policy 29:255-261

Nordhaus W (2008) A question of balance: economic models of climate change. Yale University Press, New Haven

Nordhaus W (2014) Estimates of the social cost of carbon: concepts and results from the DICE-2013R model and alternative approaches. J Assoc Environ Resour Econ 1(1):273-312

Popp D (2004) ENTICE: endogenous technological change in the DICE model of global warming. J Environ Econ Manag 48:742-768

Popp D, Newell R, Jaffe A (2010) Energy, the environment, and technological change. In: Halland B, Rosenberg N (eds) Handbook of the economics of innovation. Academic Press, Burlington, pp 873-938

Rezai A, Foley D, Taylor L (2012) Global warming and economic externalities. Econ Theor 49:329-351

Rezai A, van der Ploeg R (2016) Intergenerational inequality aversion, growth and the role of damages: Occam's rule for the social cost of carbon. J Assoc Environ Resour Econ 3(2):499-522

Rogoff K (1985) The optimal degree of commitment to an intermediate monetary target. Quart J Econ 100(4):1169-1190

Schmitt A (2013) Second-best environmental taxation in dynamic models without commitment. IIES, University of Stockholm, Stockholm

Sinn HW (2008) Public policies against global warming. Int Tax Public Finance 15(4):360-394

Stern N (2007) Econ Clim Change Stern Rev. Cambridge University Press, Cambridge

Stern N (2013) The structure of economic modeling of the potential impacts of climate change. J Econ Lit 51(3):838-859

Tiang T, Popp D (2014). The learning process and technological change in wind power: evidence from China's CDM wind projects, NBER Working Paper No. 19921. NBER, Cambridge

Tsur Y, Zemel A (2005) Scarcity, growth and R\&D. J Environ Econ Manag 49(3):484-499

Weitzman M (2010) What is the "damage function" for global warming- and what difference does it make? Clim Change Econ 1:57-69

van der Ploeg F (2016) Second-best carbon taxation in the global economy: the green paradox and carbon leakage revisited. J Environ Econ Manag 78:85-105

van der Ploeg F, de Zeeuw A (2013) Climate policy and catastrophic change: be prepared and avert risk, Research Paper 118. OxCarre, University of Oxford, Oxford

van der Zwaan BC, Gerlagh R, Klaassen G, Schrattenholzer L (2002) Endogenous technical change in climate change modelling. Energy Econ 24:1-19 